\title{
FORMULASI PROPORSI STYROFOAM TERHADAP PASIR MERAPI DAN PENGARUHNYA PADA KUAT TEKAN DAN KUAT LENTUR BATAKO RINGAN
}

\section{Imam Trianggoro Saputro}

\author{
Staf Pengajar Program Studi Teknik Sipil, Fakultas Teknik, \\ Universitas Muhammadiyah Sorong \\ Email : Imam.civil10@gmail.com
}

Diterima:15 Agustus 2017. Disetujui:19 September 2017. Dipublikasikan:1 Oktober 2017

\begin{abstract}
ABSTRAK
Pada saat ini, dunia konstruksi mengalami perkembangan yang pesat. Inovasi terhadap bata sebagai bahan bangunan banyak dilakukan. Hal ini karena bata konfensional cukup berat dengan berat volume lebih besar dari $1850 \mathrm{~kg} / \mathrm{m}^{3}$. Batako ringan dihasilkan dengan mencampurkan material ringan ke dalam batako yaitu styrofoam. Styrofoam merupakan material ringan yang banyak dihasilkan dari barang buangan sehingga mudah diperoleh. Penelitian ini mencoba membuat batako ringan dengan mencampurkan bahan ringan styrofoam ke dalam batako. Tujuan penelitian ini untuk mengetahui formulasi proporsi,berat volume, kuat tekan, dan kuat lentur dari batako styrofoam. Batako dibuat dari campuran semen, pasir, dan styrofoam. Proses pembuatan batako dilakukan dengan menggantikan volume agregat terhadap styrofoam sebesar 15\%, 30\%, 45\%, dan 60\%. Benda uji kuat tekan berupa silinder sedangkan benda uji kuat lentur berupa balok. Klasifikasi kuat tekan dilakukan menurut SNI 03-0349-1989. Hasil pengujian sampel silinder tanpa Styrofoam dan sampel silinder dengan penggantian volume styrofoam sebesar $15 \%, 30 \%, 45 \%$, dan $60 \%$ menghasilkan berat volume yaitu $2052,92 \mathrm{~kg} / \mathrm{m}^{3}, 1866,58 \mathrm{~kg} / \mathrm{m}^{3}, 1639,01 \mathrm{~kg} / \mathrm{m}^{3}, 1396,26$ $\mathrm{kg} / \mathrm{m}^{3}$, dan $1044,68 \mathrm{~kg} / \mathrm{m}^{3}$. Kuat tekan rata-rata setiap variasi silinder sebesar 8,703 MPa, 7,160 MPa, 6,012 MPa, 4,881 MPa, dan 2,876 MPa. Kuat Lentur rata-rata setiap variasi balok sebesar 1,810 MPa, 1,552 MPa, 1,495 MPa, 1,301 MPa, dan 0,883 MPa. Sesuai dengan hasil pengujian, batako dengan rasio styrofoam 30\% dan 45\% mempunyai kekuatan yang memenuhi klasifikasi III (SNI 03-0349-1989). Dengan memilih yang ringan dari 2 variasi batako, variasi styrofoam $45 \%$ yang paling sesuai untuk direkomendasikan.
\end{abstract}

Kata kunci: Bata ringan, styrofoam, inovasi material, pasir Merapi, formulasi proporsi.

\section{PENDAHULUAN}

Pada saat ini perkembangan di bidang konstruksi bangunan mengalami kemajuan yang pesat. Dengan semakin pesatnya pertumbuhan pengetahuan dan teknologi di bidang konstruksi mendorong untuk lebih memperhatikan standar mutu serta produktivitas kerja. Teknologi di bidang konstruksi dapat berperan serta dalam meningkatkan sebuah pembangunan konstruksi dengan lebih berkualitas. Batako ringan merupakan suatu inovasi yang dibuat dengan tujuan untuk mempermudah proses pengerjaan dinding sehingga lebih mudah dan cepat. Batako ringan dalam pengertian umum adalah batako yang memiliki berat satuan berkisar antara $600-1850 \mathrm{~kg} / \mathrm{m}^{3}$. Styrofoam sangat mudah dijumpai karena banyak digunakan terutama sebagai pembungkus alat elektronik. Batako ringan tanpa pori, yaitu batako ringan yang dihasilkan dengan menambah agregat ringan dalam proses pembuatannya. Tujuan mencampurkan agregat ringan adalah untuk mengurangi 
berat batako. Banyak kemungkinan agregat ringan yang digunakan antara lain styrofoam, batu apung, perlit, serat sintesis, dan lain-lain.

Penelitian ini membuat batako ringan menggunakan campuran agregat pengisi berupa styrofoam dengan pasir Merapi. Styrofoamdicampurkan ke dalam batako karena styrofoam memiliki berat yang ringan. Styrofoam yang dicampurkan dapat dianggap sebagai pori-pori pada batako sehingga menjadi batako ringan akibat memiliki pori-pori didalamnya. Hal ini yang mendasari penelitian batako ringan dengan menggunakan campuran styrofoam ini dilakukan. Pengujian yang dilakukan pada batako styrofoam yaitu pengujian kuat tekan dan pengujian kuat lentur.

\section{Tujuan Penelitian}

Penelitian ini memiliki tujuan, diantaranya

1. Mengetahui formulasi campuran batako ringan menggunakan styrofoam, agregat pasir Merapi, dan Semen Portland.

2. Mengetahui variasi yang kuat tekan dan kuat lentur optimal dari batako ringan styrofoam.

3. Mengetahui hubungan kadar styrofoam dan kuat tekan untuk campuran batako ringan styrofoam.

\section{Manfaat Penelitian}

Manfaat penelitian yang diharapkan adalah sebagai berikut ini :

1. Penelitian ini diharapkan memberikan informasi bagi perkembangan ilmu teknologi batako ringan dengan menggunakan bahan styrofoam.

2. Dengan penelitian ini diharapkan teknologi beton ringan ke depannya menjadi lebih baik lagi dari sebelumnya.
3. Memberikan informasi mengenai pemanfaatan limbah styrofoam agar tidak terbuang dengan percuma.

\section{Batasan Masalah}

Batasan-batasan masalah penelitian ini sebagai berikut ini :

1. Agregat halus yang digunakan adalah pasir yang berasal dari kali Boyong/Merapi.

2. Perbandingan yang digunakan adalah $1 \mathrm{PC}: 5$ (Pasir + styrofoam)

3. Fas (faktor air semen) digunakan 0,6

4. Bahan tambah yang digunakan adalah styrofoam berbentuk bulat yang di peroleh dari pasar lokal dengan ukuran butir bervariasai antara $3-6 \mathrm{~mm}$.

5. Penelitian ini menggunakan 5 (lima) jenis variasi. Variasi yang digunakan adalah sebagai berikut ini:

a. Variasi AN yaitu Penggunaan 0\% volume styrofoam terhadap volume total dari agregat yang digunakan.

b. Variasi A1 yaitu Penggunaan $15 \%$ volume styrofoam terhadap volume total dari agregat yang digunakan.

c. Variasi A2 yaitu Penggunaan $30 \%$ volume styrofoam terhadap volume total dari agregat yang digunakan.

d. Variasi A3 yaitu Penggunaan $45 \%$ volume styrofoam terhadap volume total dari agregat yang digunakan.

e. Variasi A4 yaitu Penggunaan $60 \%$ volume styrofoam terhadap volume total dari agregat yang digunakan

\section{METODOLOGI PENELITIAN}

Pada penelitian ini menggunakan jenis penelitian eksperimen yaitu melakukan serangkaian percobaan terhadap batako ringan yang menggunakan bahan dasar styrofoam dan juga agregat pasir Merapi. Pengujian di Laboratorim menghasilkan data dari masing-masing 


\section{Jurnal Rancang Bangun 3(1) 18-27 2017}

sampel. Data tersebut merupakan data awal hasil pengujian.

Data hasil Laboratorium masih harus dianalisis untuk mengetahui hasil dari penelitian. Hasil tersebut dapat menunjukan suatu kesimpulan tentang variasi yang baik dari hasil serangkaian pengujian. Berikut ini terdapat bagan alir penelitian pada Gambar 1 berikut :

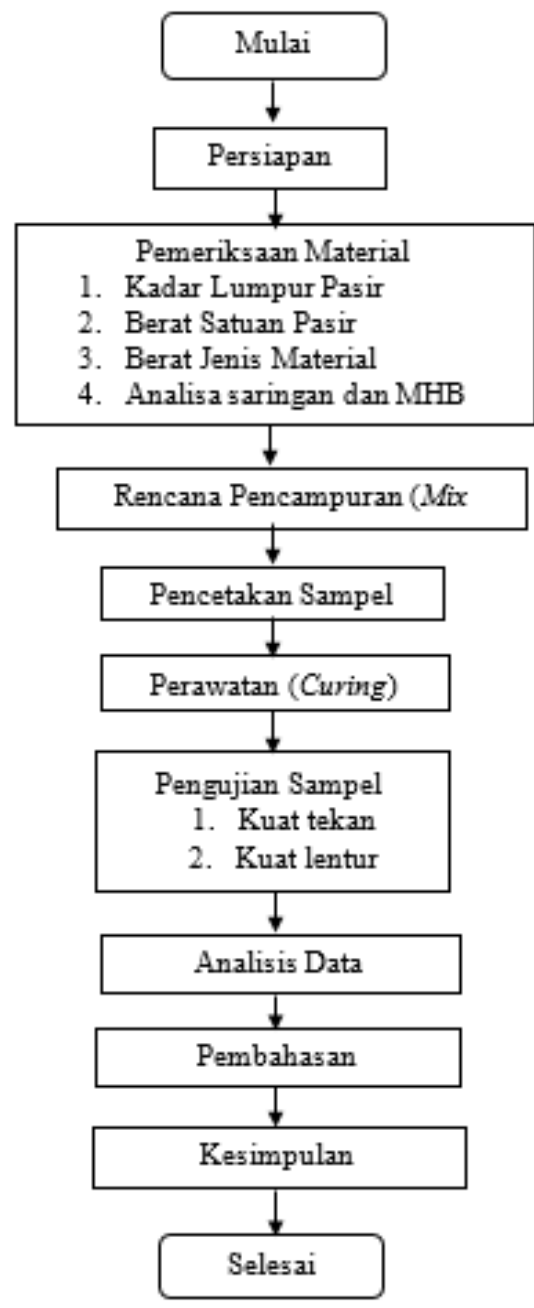

Gambar 1 Bagan Alir Penelitian

\section{HASIL PENELITIAN}

\section{Berat Jenis}

Berat jenis pasir/agregat halus jenuh kering muka (SSD) yang berasal dari sungai Boyong didapatkan sebesar $2,53 \mathrm{~kg} / \mathrm{m}^{3}$ dengan tingkat penyerapan air sebesar 4,71 $\%$.

\section{Berat Volume Pasir dan Semen}

Hasil pemeriksaan berat volume pasir dalam keadaan gembur sebesar 1481,3 $\mathrm{kg} / \mathrm{m}^{3}$ sedangkan pemeriksaan berat volume pasir dalam keadaan padat sebesar $1696,5 \mathrm{~kg} / \mathrm{m}^{3}$. Pemeriksaan berat volume semen didapatkan $1492,4 \mathrm{~kg} / \mathrm{m}^{3}$.

\section{Modulus Halus Butir}

Hasil pemeriksaan modulus halus butir pada pasir sungai Boyong didapatkan sebesar 2,101 dan termasuk pada jenis pasir gradasi III.

\section{Berat Volume Styrofoam}

Styrofoam berbentuk butiran dengan ukuran 3-6 mm. setelah dilakukan pemeriksaan didapatkan berat volume sebesar $11,03 \mathrm{~kg} / \mathrm{m}^{3}$.

\section{Perencanaan Pencampuran} (Mix Design)

Perencanaan pencampuran dilakukan untuk menghitung kebutuhan campuran yang diperlukan dalam penelitian. Kebutuhan pencampuran sesuai dengan benda uji yang akan dibuat. Jumlah benda uji dapat dilihat pada Tabel 1 berikut.

Tabel 1Jumlah Benda Uji Penelitian

\begin{tabular}{|l|c|c|}
\hline $\begin{array}{c}\text { Jenis } \\
\text { sampel }\end{array}$ & $\begin{array}{c}\text { Tipe } \\
\text { Pengujian }\end{array}$ & $\begin{array}{c}\text { Jumlah } \\
\text { (Buah) }\end{array}$ \\
\hline Silinder A1 & Kuat Tekan & 15 \\
\hline Silinder A2 & Kuat Tekan & 15 \\
\hline Silinder A3 & Kuat Tekan & 15 \\
\hline Silinder A4 & Kuat Tekan & 15 \\
\hline Silinder AN & Kuat Tekan & 15 \\
\hline Batako A1 & Kuat Tekan & 3 \\
\hline Batako A2 & Kuat Tekan & 3 \\
\hline Batako A3 & Kuat Tekan & 3 \\
\hline Batako A4 & Kuat Tekan & 3 \\
\hline Batako AN & Kuat Tekan & 3 \\
\hline Balok A1 & Kuat Lentur & 3 \\
\hline Balok A2 & Kuat Lentur & 3 \\
\hline Balok A3 & Kuat Lentur & 3 \\
\hline Balok A4 & Kuat Lentur & 3 \\
\hline Balok AN & Kuat Lentur & 3 \\
\hline \multicolumn{2}{|c|}{ Total } & 105 \\
\hline
\end{tabular}


Variasi yang dilakukan terhadap agregat. Dalam penelitian ini terdapat 5 variasi yang digunakan. variasi tersebut tersaji pada Tabel 2 berikut.

Tabel 2Variasi Agregat

\begin{tabular}{|c|c|c|}
\hline $\begin{array}{c}\text { Variasi } \\
\text { Agregat }\end{array}$ & $\begin{array}{c}\text { Pasir } \\
(\boldsymbol{\%})\end{array}$ & $\begin{array}{c}\text { Styrofoam } \\
(\%)\end{array}$ \\
\hline AN & 100 & 0 \\
\hline A1 & 85 & 15 \\
\hline A2 & 70 & 30 \\
\hline A3 & 55 & 45 \\
\hline A4 & 40 & 60 \\
\hline
\end{tabular}

Dalam penelitian ini, styrofoam yang digunakan memiliki ukuran butir 3-6 mm sehingga akan menghasilkan rongga antara butiran yang cukup besar. Berdasarkan hasil coba-coba ditentukan setiap peningkatan $15 \%$ volume, untuk mengisi rongga styrofoam diperlukan sekitar 5\% material dari total kebutuhan pencampuran. Oleh karena itu, faktor rongga ditentukan sesuai pada Tabel 3.

Tabel 3Faktor Rongga Styrofoam

\begin{tabular}{|c|c|}
\hline \multicolumn{2}{|c|}{ Faktor Rongga Styrofoam (FRs) } \\
\hline Variasi & FRs \\
\hline A1 & 1.05 \\
\hline A2 & 1.1 \\
\hline A3 & 1.15 \\
\hline A4 & 1.2 \\
\hline
\end{tabular}

maka setelah melakukan serangkaian percobaan didapatkan formulasi Perhitungan kebutuhan campuran mengikuti persamaan sebagai berikut :

Proporsi bahan total

$=1,1 \times$ Pkb $\times$ V x n $\times$ FRs

Keterangan :

$\mathrm{Pkb}=$ Proporsi kebutuhan bahan $\left(\mathrm{kg} / \mathrm{m}^{3}\right)$

$$
\begin{array}{ll}
\mathrm{V} & =\text { Volume sampel }\left(\mathrm{m}^{3}\right) \\
\mathrm{n} & =\text { Jumlah sampel } \\
1,1 & =\text { Faktor Pengali } \\
\text { FRs } & =\text { Faktor Rongga Styrofoam }
\end{array}
$$

\section{Berat Volume Silinder}

Hasil pengujian terhadap 5 variasi didapatkan berat volume rata-rata dari tiap variasi. Berat volume dan persentase penurunannya kemudian direkapitulasi sesuai dengan masing-masing variasi. Penurunan berat volume terjadi seiring dengan jumlah persentase Styrofoam dalam pencampuran. Hasil rekapitulasi dari berat volume tersaji pada Tabel 4 sedangkan penurunan berat volume silinder styrofoam yang terjadi setiap variasi terlihat pada Grafik 1 seperti di bawah ini.

Tabel 4Penurunan Berat Volume RataRata Beton Silinder

\begin{tabular}{|c|c|c|c|c|}
\hline No & Variasi & $\%$ styrofoam & $\begin{array}{c}\text { Berat } \\
\text { Volume } \\
\text { Rata-Rata } \\
\left(\mathrm{kg} / \mathrm{m}^{3}\right)\end{array}$ & $\begin{array}{c}\text { Penurunan } \\
\text { Berat } \\
\text { Volume } \\
(\%)\end{array}$ \\
\hline 1 & $\mathrm{AN}$ & $0 \%$ & 2052.9153 & 100.00 \\
\hline 2 & $\mathrm{~A} 1$ & $15 \%$ & 1866.5833 & 90.92 \\
\hline 3 & $\mathrm{~A} 2$ & $30 \%$ & 1639.0159 & 79.84 \\
\hline 4 & $\mathrm{~A} 3$ & $45 \%$ & 1396.2566 & 68.01 \\
\hline 5 & $\mathrm{~A} 4$ & $60 \%$ & 1044.6804 & 50.89 \\
\hline
\end{tabular}

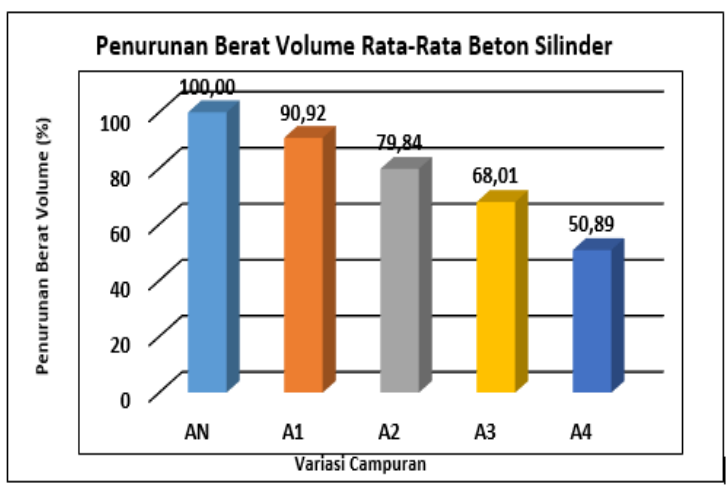

Grafik 1 Penurunan Berat Volume

Terhadap Variasi Campuran

\section{Kuat Tekan Silinder}




\section{Jurnal Rancang Bangun 3(1) 18-27 2017}

Hasil pengujian terhadap 5 (lima) variasi didapatkan kuat tekan rata-rata yang diperoleh dari tiap variasinya. Kuat tekan rata-rata tersebut kemudian direkapitulasi sesuai dengan masing-masing variasi agar mudah melihat karakteristiknya. Hasil rekapitulasi kuat tekan rata-rata dari masing-masing variasi tersaji pada Tabel 5 sedangkan hubungan perbandingan antara persentase penggunaan styrofoam dengan kuat tekan rata-rata silinder styrofoam terlihat pada Grafik 2 seperti berikut.

Tabel 5 Hasil Kuat Tekan Silinder Dari Tiap Variasi

\begin{tabular}{|c|c|c|c|}
\hline No & Variasi & $\begin{array}{c}\% \\
\text { styrofoam }\end{array}$ & $\begin{array}{c}\text { f'c rata-rata } \\
(\mathrm{MPa})\end{array}$ \\
\hline 1 & $\mathrm{AN}$ & $0 \%$ & 8.70305 \\
\hline 2 & $\mathrm{~A} 1$ & $15 \%$ & 7.16057 \\
\hline 3 & $\mathrm{~A} 2$ & $30 \%$ & 6.01236 \\
\hline 4 & $\mathrm{~A} 3$ & $45 \%$ & 4.88133 \\
\hline 5 & $\mathrm{~A} 4$ & $60 \%$ & 2.87566 \\
\hline
\end{tabular}

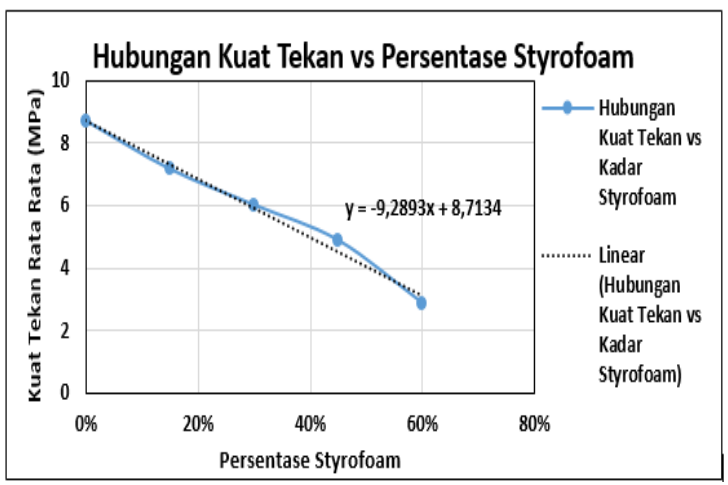

Grafik 2 Hubungan Kuat Tekan dan

Persentase Styrofoam

Dari Grafik 2 didapatkan hubungan rumus empiris berdasarkan perhitungan Microsoft Excel sebagai berikut ini.
Keterangan:

f'c = Kuat Tekan Silinder Styrofoam

(MPa)

$\mathrm{X}=$ Kadar Styrofoam terhadap volume agregat

Salah satu tujuan dari penelitian ini bahwa Silinder beton tersebut merepresentasikan kuat tekan campuran yang akan digunakan pada batako. Kuat tekan untuk batako memiliki syarat-syarat tertentu.Persyaratan tersebut sesuai SNI 03-0349-1989 yang terlihat pada Tabel 1. Sesuai kriteria yang disyaratkan, maka dari hasil pengujian diperoleh mutu dari sampel yang diuji. Hasil klasifikasi mutu terlihat pada Grafik 3

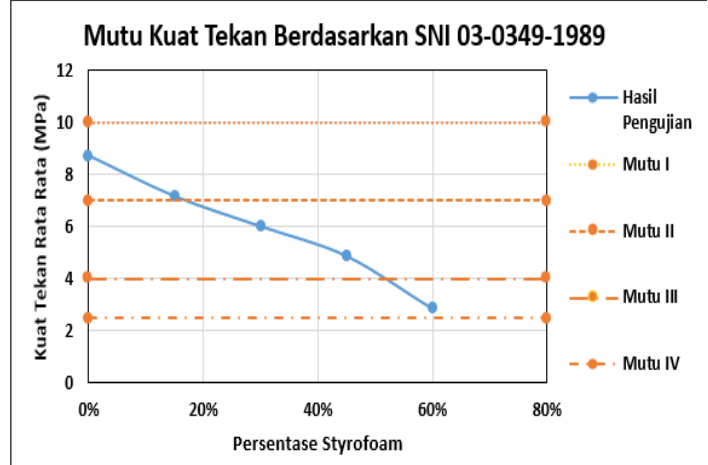

Grafik 3Klasifikasi Mutu Berdasarkan SNI 03-0349-1989

\section{Modulus Elastisitas}

Besarnya nilai modulus elastisitas sampelnya diukur pada penelitian ini. Hasil perhitungan modulus elastisitas dilakukan terhadap hasil percobaan yang diperoleh. kemudian dicari persamaan rumus empiris hasil percobaan dengan menggunakan pendekatan persamaan pada peraturanACI 318-83M sehingga didapat sebagai berikut. Terlihat pada Tabel 6

$f^{\prime} c \quad=-9.2893 X+8.7134$

Tabel 6 Perhitungan Pendekatan Rumus Empiris

\begin{tabular}{|c|c|c|c|c|c|c|c|c|}
\hline Sampel & $\mathrm{Wc}$ & $\mathrm{Wc}^{1.5}$ & $\mathrm{fc}$ & $\sqrt{ } \mathrm{f}^{\prime} \mathrm{c}$ & $\mathrm{Wc}^{1.5} \sqrt{ } \mathrm{f}^{\prime} \mathrm{c}$ & $\mathrm{Ec}$ & $\mathrm{Wc}^{1.5} \sqrt{ } \mathrm{f}^{\prime} \mathrm{c} / \mathrm{Ec}$ & $\begin{array}{c}\text { Angka } \\
\text { pengali }\end{array}$ \\
\hline $\mathrm{AN}(1)$ & 2100.617 & 96276.48 & 8.816 & 2.969 & 285869.4 & 12823.97 & 0.045 & 0.046 \\
\hline
\end{tabular}




\section{Jurnal Rancang Bangun 3(1) 18-27 2017}

\begin{tabular}{|c|c|c|c|c|c|c|c|c|}
\hline $\mathrm{AN}(2)$ & 2028.824 & 91383.26 & 10.701 & 3.271 & 298942 & 14034.62 & 0.047 & \\
\hline $\mathrm{AN}(3)$ & 2044.173 & 92422.22 & 9.414 & 3.068 & 283578.3 & 13449.16 & 0.047 & \\
\hline $\mathrm{AN}(4)$ & 2077.356 & 94681.79 & 9.527 & 3.087 & 292238.7 & 13609.58 & 0.047 & \\
\hline $\mathrm{AN}(5)$ & 2017.104 & 90592.51 & 7.175 & 2.679 & 242669.8 & 10630.24 & 0.044 & \\
\hline $\mathrm{AN}(6)$ & 2070.727 & 94228.93 & 8.236 & 2.870 & 270414.7 & 11978.97 & 0.044 & \\
\hline $\mathrm{AN}(7)$ & 2075.031 & 94522.84 & 8.539 & 2.922 & 276211.2 & 12198.63 & 0.044 & \\
\hline $\mathrm{AN}(8)$ & 2043.734 & 92392.48 & 10.155 & 3.187 & 294432 & 13785.35 & 0.047 & \\
\hline $\mathrm{AN}(9)$ & 2073.789 & 94438.04 & 8.013 & 2.831 & 267332.1 & 11784.18 & 0.044 & \\
\hline $\mathrm{AN}(10)$ & 2018.138 & 90662.18 & 8.318 & 2.884 & 261480.5 & 11757.09 & 0.045 & \\
\hline $\mathrm{AN}(11)$ & 2062.409 & 93661.71 & 7.304 & 2.703 & 253130.3 & 11237.01 & 0.044 & \\
\hline $\mathrm{AN}(12)$ & 2043.478 & 92375.1 & 8.533 & 2.921 & 269832.8 & 13543.75 & 0.050 & \\
\hline $\mathrm{AN}(13)$ & 2061.03 & 93567.8 & 9.490 & 3.081 & 288241.7 & 13319.13 & 0.046 & \\
\hline $\mathrm{AN}(14)$ & 2057.367 & 93318.51 & 8.069 & 2.841 & 265084.1 & 11527.46 & 0.043 & \\
\hline $\mathrm{AN}(15)$ & 2019.954 & 90784.61 & 8.254 & 2.873 & 260825.3 & 11584.84 & 0.044 & \\
\hline $\mathrm{A} 1(1)$ & 1869.476 & 80831.36 & 7.605 & 2.758 & 222917.1 & 10674.36 & 0.048 & \multirow{15}{*}{0.047} \\
\hline $\mathrm{A} 1(2)$ & 1868.556 & 80771.67 & 6.867 & 2.620 & 211655.5 & 10097.92 & 0.048 & \\
\hline A1(3) & 1869.486 & 80832 & 7.440 & 2.728 & 220479.8 & 10191.73 & 0.046 & \\
\hline $\mathrm{A} 1(4)$ & 1848.051 & 79445.82 & 6.972 & 2.640 & 209768.5 & 9896.954 & 0.047 & \\
\hline A1(5) & 1834.017 & 78542.58 & 7.209 & 2.685 & 210885.4 & 10298.75 & 0.049 & \\
\hline $\mathrm{A} 1(6)$ & 1875.974 & 81253.15 & 6.718 & 2.592 & 210596.5 & 9771.228 & 0.046 & \\
\hline $\mathrm{A} 1(7)$ & 1923.977 & 84391.72 & 7.754 & 2.785 & 235001.7 & 10514.3 & 0.045 & \\
\hline A1(8) & 1842.896 & 79113.64 & 7.753 & 2.784 & 220280.2 & 10767.52 & 0.049 & \\
\hline A1(9) & 1835.295 & 78624.7 & 7.003 & 2.646 & 208058.7 & 10011.56 & 0.048 & \\
\hline $\mathrm{A} 1(10)$ & 1897.277 & 82641.09 & 7.028 & 2.651 & 219089 & 9933.968 & 0.045 & \\
\hline $\mathrm{A} 1(11)$ & 1864.172 & 80487.58 & 6.919 & 2.630 & 211710.6 & 9883.926 & 0.047 & \\
\hline A1(12) & 1883.148 & 81719.66 & 6.253 & 2.501 & 204348.5 & 9438.522 & 0.046 & \\
\hline A1(13) & 1810.015 & 77005.78 & 6.442 & 2.538 & 195452.9 & 9544.071 & 0.049 & \\
\hline A1(14) & 1886.636 & 81946.83 & 7.731 & 2.780 & 227851.2 & 10482.78 & 0.046 & \\
\hline A1(15) & 1889.773 & 82151.33 & 7.715 & 2.778 & 228186.6 & 10972.34 & 0.048 & \\
\hline A2(1) & 1634.861 & 66102.98 & 5.189 & 2.278 & 150580.8 & 7983.321 & 0.053 & \multirow{12}{*}{0.055} \\
\hline $\mathrm{A} 2(2)$ & 1676.113 & 68620.68 & 6.264 & 2.503 & 171748.4 & 9280.502 & 0.054 & \\
\hline $\mathrm{A} 2(3)$ & 1629.885 & 65801.42 & 5.623 & 2.371 & 156037.2 & 8487.891 & 0.054 & \\
\hline A2(4) & 1640.348 & 66436.1 & 6.044 & 2.459 & 163333.7 & 8791.65 & 0.054 & \\
\hline $\mathrm{A} 2(5)$ & 1654.041 & 67269.68 & 4.992 & 2.234 & 150302.5 & 7739.876 & 0.051 & \\
\hline $\mathrm{A} 2(6)$ & 1644.517 & 66689.52 & 6.015 & 2.453 & 163564.1 & 8846.102 & 0.054 & \\
\hline $\mathrm{A} 2(7)$ & 1629.369 & 65770.22 & 6.870 & 2.621 & 172386.2 & 9641.873 & 0.056 & \\
\hline A2(8) & 1613.382 & 64804.6 & 6.282 & 2.506 & 162427.7 & 9482.5 & 0.058 & \\
\hline A2(9) & 1642.376 & 66559.32 & 6.259 & 2.502 & 166513.8 & 9103.534 & 0.055 & \\
\hline $\mathrm{A} 2(10)$ & 1595.008 & 63700.72 & 5.941 & 2.437 & 155262 & 8967.179 & 0.058 & \\
\hline $\mathrm{A} 2(11)$ & 1657.098 & 67456.25 & 6.960 & 2.638 & 177966.6 & 9749.317 & 0.055 & \\
\hline A2(12) & 1600.387 & 64023.21 & 5.374 & 2.318 & 148415.6 & 8267.436 & 0.056 & \\
\hline
\end{tabular}




\section{Jurnal Rancang Bangun 3(1) 18-27 2017}

\begin{tabular}{|c|c|c|c|c|c|c|c|c|}
\hline $\mathrm{A} 2(13)$ & 1641.252 & 66491.02 & 6.819 & 2.611 & 173628.2 & 9570.393 & 0.055 & \\
\hline $\mathrm{A} 2(14)$ & 1644.871 & 66711.03 & 5.226 & 2.286 & 152500.4 & 7741.812 & 0.051 & \\
\hline $\mathrm{A} 2(15)$ & 1681.731 & 68965.98 & 6.327 & 2.515 & 173468.1 & 9372.72 & 0.054 & \\
\hline $\mathrm{A} 3(1)$ & 1381.577 & 51352.6 & 4.233 & 2.057 & 105651.8 & 6613.772 & 0.063 & \multirow{15}{*}{0.065} \\
\hline $\mathrm{A} 3(2)$ & 1375.532 & 51015.97 & 5.154 & 2.270 & 115820.4 & 7929.477 & 0.068 & \\
\hline $\mathrm{A} 3(3)$ & 1346.251 & 49395.68 & 4.562 & 2.136 & 105506.2 & 7156.457 & 0.068 & \\
\hline $\mathrm{A} 3(4)$ & 1385.831 & 51590 & 4.853 & 2.203 & 113645.8 & 7465.564 & 0.066 & \\
\hline $\mathrm{A} 3(5)$ & 1375.201 & 50997.56 & 4.858 & 2.204 & 112405.4 & 7620.707 & 0.068 & \\
\hline $\mathrm{A} 3(6)$ & 1339.569 & 49028.37 & 4.012 & 2.003 & 98205.17 & 7464.408 & 0.076 & \\
\hline $\mathrm{A} 3(7)$ & 1446.059 & 54989.41 & 5.197 & 2.280 & 125354.9 & 7698.754 & 0.061 & \\
\hline $\mathrm{A} 3(8)$ & 1400.13 & 52390.49 & 5.523 & 2.350 & 123120 & 8181.798 & 0.066 & \\
\hline A3(9) & 1522.133 & 59385.28 & 4.918 & 2.218 & 131689.9 & 7565.437 & 0.057 & \\
\hline $\mathrm{A} 3(10)$ & 1430.423 & 54099.94 & 4.773 & 2.185 & 118189 & 6818.085 & 0.058 & \\
\hline A3(11) & 1451.562 & 55303.62 & 4.115 & 2.029 & 112192.4 & 6584.76 & 0.059 & \\
\hline $\mathrm{A} 3(12)$ & 1409.285 & 52905.2 & 4.545 & 2.132 & 112794.7 & 6993.06 & 0.062 & \\
\hline $\mathrm{A} 3(13)$ & 1323.478 & 48147.63 & 4.747 & 2.179 & 104896.9 & 7302.336 & 0.070 & \\
\hline A3(14) & 1356.836 & 49979.4 & 5.812 & 2.411 & 120487 & 8302.33 & 0.069 & \\
\hline $\mathrm{A} 3(15)$ & 1399.983 & 52382.26 & 5.919 & 2.433 & 127442.8 & 8455.982 & 0.066 & \\
\hline $\mathrm{A} 4(1)$ & 965.7814 & 30013.61 & 2.524 & 1.589 & 47683.22 & 4695.871 & 0.098 & \multirow{15}{*}{0.087} \\
\hline $\mathrm{A} 4(2)$ & 1005.329 & 31875.91 & 2.630 & 1.622 & 51695.3 & 4962.508 & 0.096 & \\
\hline $\mathrm{A} 4(3)$ & 1030.201 & 33066.12 & 2.310 & 1.520 & 50260.03 & 3932.521 & 0.078 & \\
\hline $\mathrm{A} 4(4)$ & 1055.807 & 34306.54 & 3.220 & 1.794 & 61559.74 & 5480.649 & 0.089 & \\
\hline $\mathrm{A} 4(5)$ & 1087.447 & 35860.17 & 3.579 & 1.892 & 67845.26 & 5965.722 & 0.088 & \\
\hline $\mathrm{A} 4(6)$ & 1098.707 & 36418.57 & 3.658 & 1.912 & 69650.09 & 6096.018 & 0.088 & \\
\hline $\mathrm{A} 4(7)$ & 1026.594 & 32892.59 & 2.608 & 1.615 & 53117.14 & 4851.708 & 0.091 & \\
\hline $\mathrm{A} 4(8)$ & 961.0632 & 29793.94 & 1.879 & 1.371 & 40837.65 & 3495.322 & 0.086 & \\
\hline $\mathrm{A} 4(9)$ & 1027.115 & 32917.65 & 3.451 & 1.858 & 61150.67 & 5874.039 & 0.096 & \\
\hline $\mathrm{A} 4(10)$ & 1054.221 & 34229.27 & 2.254 & 1.501 & 51388.12 & 3756.461 & 0.073 & \\
\hline $\mathrm{A} 4(11)$ & 1067.621 & 34883.95 & 2.876 & 1.696 & 59157.17 & 5112.59 & 0.086 & \\
\hline $\mathrm{A} 4(12)$ & 1064.921 & 34751.7 & 3.043 & 1.745 & 60625.1 & 5292.793 & 0.087 & \\
\hline A4(13) & 1120.444 & 37504.68 & 3.424 & 1.850 & 69396.32 & 5612.376 & 0.081 & \\
\hline A4(14) & 1084.983 & 35738.33 & 3.205 & 1.790 & 63983.54 & 5574.428 & 0.087 & \\
\hline $\mathrm{A} 4(15)$ & 1019.97 & 32574.73 & 2.474 & 1.573 & 51234.3 & 4302.215 & 0.084 & \\
\hline
\end{tabular}

$\mathrm{Ec} \quad=\mathrm{XW} \sqrt{1.5} \sqrt{f^{\prime} c}$

Keterangan :

$\mathrm{X}=$ Pengali Rata-Rata

Ec $\quad=$ modulus elastisitas beton

(MPa)

$W c \quad=$ berat satuan beton $\left(\mathrm{kgf} / \mathrm{m}^{3}\right)$

fc $\quad=$ kuat tekan beton uji silinder

(MPa)
Sehingga didapatkan rumus empiris untuk variasi silinder tanpa Styrofoam sebagai berikut :

Ec $=0,046 W c^{1.5} \sqrt{f^{\prime} c}$

Untuk variasi yang menggunakan Styrofoamdengan kadar sebesar 15\%, 30\%, $45 \%$, dan $60 \%$. Perhitungan pendekatan 


\section{Jurnal Rancang Bangun 3(1) 18-27|2017}

rumus empiris modulus elastisitas dilakukan sesuai pada Tabel 6 di atas. Dari hasil perhitungan tersebut maka diperoleh rumus empiris sebagai berikut ini.

$$
\begin{aligned}
X \text { rerata } & =\frac{\sum X}{n} \\
& =\frac{0,047+0,055+0,065+0,087}{4} \\
& =0.064
\end{aligned}
$$

Sehingga didapatkan pendekatan rumus empiris untuk variasi silinder Styrofoam sebagai berikut :

Ec $=0,064 W c^{1.5} \sqrt{f^{\prime} c}$

untuk: $1000 \leq W c \leq 1900 \mathrm{kgf} / \mathrm{m}^{3}$

\section{Kuat Lentur Balok}

Pengujian kuat lentur balok beton Styrofoam dilakukan untuk memperoleh nilai kuat lentur balok beton styrofoam maksimal dari sampel yang diberi pembebanan.

Hasil pengujian kuat lenturrata-rata balokmasing-masing sampel tiap variasi dan tingkat penurunan kuat lentur dari balok dapat dilihat pada Tabel 7. Hasil pengujian dapat menggambarkan pola kecenderungan yang terjadi pada setiap variasinya sehingga dapat terlihat penurunan kuat lentur rata-rata balok terhadap variasi campuran. Hasil tersebut dapat dilihat pada Grafik 4.

Tabel 7Penurunan Kuat Lentur Balok Styrofoam

\begin{tabular}{|c|c|c|c|c|}
\hline No & Variasi & $\begin{array}{c}\% \\
\text { styrofoam }\end{array}$ & $\begin{array}{c}\text { Kuat Lentur } \\
\text { Rata-Rata } \\
\left(\mathrm{kg} / \mathrm{m}^{3}\right)\end{array}$ & $\begin{array}{c}\text { Penurunan } \\
\text { Kuat Lentur } \\
(\%)\end{array}$ \\
\hline 1 & $\mathrm{AN}$ & $0 \%$ & 1.8730 & 100.00 \\
\hline 2 & $\mathrm{~A} 1$ & $15 \%$ & 1.5144 & 80.85 \\
\hline 3 & $\mathrm{~A} 2$ & $30 \%$ & 1.4162 & 75.61 \\
\hline 4 & $\mathrm{~A} 3$ & $45 \%$ & 1.2904 & 68.90 \\
\hline 5 & $\mathrm{~A} 4$ & $60 \%$ & 0.9148 & 48.84 \\
\hline
\end{tabular}

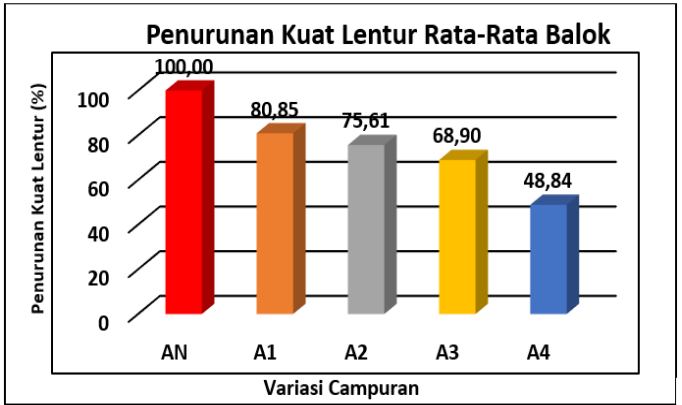

Grafik 4PenurunanKuat Lentur Rata-Rata

Dari Variasi Sampel

\section{Pola Retak Balok}

Hal ini dilakukan untuk melihat pola retak yang terjadi hasil analisis menggunakan SAP 2000 dengan hasil labolatorium. Hasil analisis SAP 2000 terdapat pada Gambar 1a dan $1 \mathrm{~b}$ sedangkan hasil labolatorium terlihat pada gambar 2a sampai $2 \mathrm{~d}$.

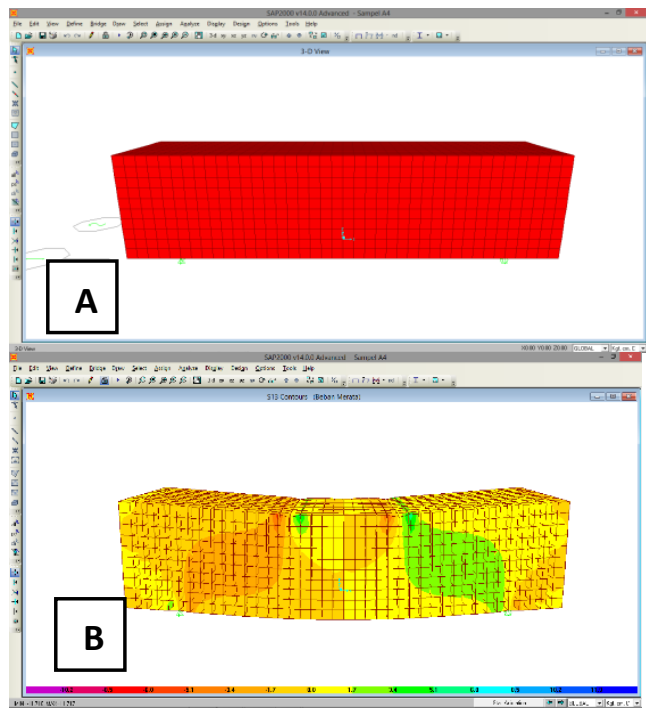

Gambar 1. Hasil analisis SAP 2000 a). sebelum dibebani, b). setelah dibebani

a). sebelum dibebani

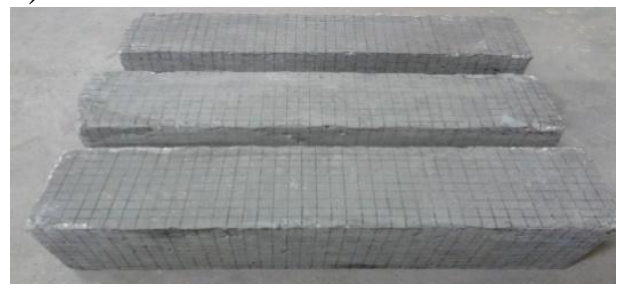


b). setelah dibebani ( sisi kiri)

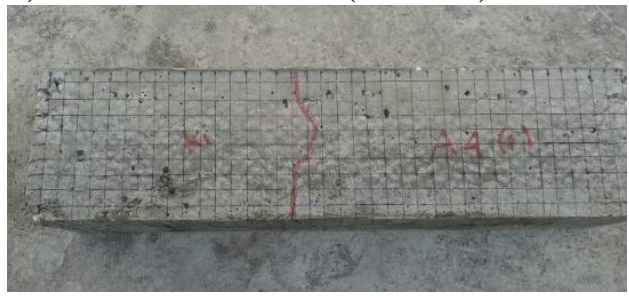

c). setelah dibebani (sisi bawah)

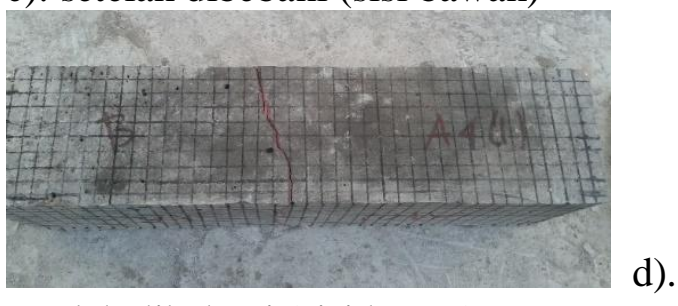

setelah dibebani (sisi kanan)

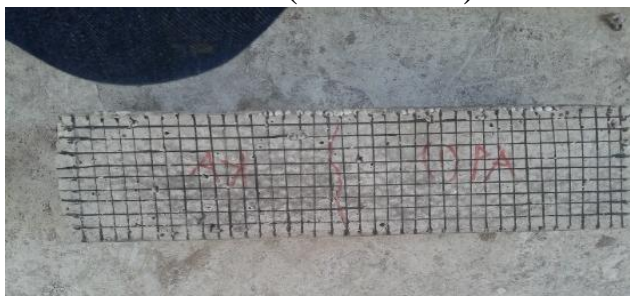

Gambar 1. Hasil Labolatorium

Berdasarkan pola retak balok diatas maka hasil analisis pada SAP 2000 pola retak yang dihasilkan terjadi karena gaya geser. Hal ini mengidentifikasikan dengan patahan yang cenderung miring sedangkan pada hasil labolatorium pola retak balok terjadi menunjukkan gagal karena lentur tetapi gaya geser pun ikut berpengaruh. Hal ini terlihat pada bagian bawah balok yang patahannya berbentuk miring.

\section{KESIMPULAN}

Berdasarkan penelitian yang telah dilakukan serta hasil analisis dan pembahasan pada bab sebelumnya, maka dapat ditarik beberapa kesimpulan sebagai berikut ini.

1. Formulasi campuran batako ringan styrofoam sebagai berikut :

Proporsi bahan total

$=1,1 \times P k b \times V \times n \times F R$

Keterangan :
$\mathrm{Pkb}=$ Proporsi kebutuhan bahan

$$
\left(\mathrm{kg} / \mathrm{m}^{3}\right)
$$

$\mathrm{V}=$ Volume sampel $\left(\mathrm{m}^{3}\right)$

$\mathrm{n}=$ Jumlah sampel

$1,1=$ Faktor Pengali

FRs $=$ Faktor Rongga Styrofoam

2. Hasil penelitian menunjukkan bahwa seiring dengan bertambahnya persentase styrofoam ke dalam campuran akan menurunkan kuat tekan dan kuat lentur dari sampel yang dihasilkan. Hal ini dikarenakan apabila semakin banyak styrofoam di dalam sampel benda uji maka porositas dari sampel tersebut akan menjadi semakin besar sehingga mutu dari beton tersebut akan menurun. Sampel yang terbaik adalah dengan kadar styrofoam $45 \%$ karena selain ringan jenis ini juga tergolong pada mutu klasifikasi III.

3. Berdasarkan hasil penelitian didapatkan rumus empiris mengenai hubungan antara kuat tekan yang dihasilkan dengan kadar styrofoam yang digunakan. rumus empiris tersebut sebagai berikut ini.

$f^{\prime} c=-9.2893 X+8.7134$

Keterangan:

$\mathrm{f}^{\prime} \mathrm{c}=$ Kuat Tekan Silinder Styrofoam (MPa)

$\mathrm{X}$ = Kadar Styrofoam terhadap volume agregat

Sewaktu pencampuran styrofoam dengan kadar $60 \%$ menggunakan faktor air semen (fas) sebesar 0,6 menghasilkan campuran yang sangat cair.

\section{SARAN}

Untuk menindaklanjuti penelitian ini, diperlukan beberapa koreksi yang harus diperhatikan agar dapat dijadikan sebagai 


\section{Jurnal Rancang Bangun 3(1) 18-27 2017}

pedoman dan acuan bagi penelitianpenelitian selanjutnya agar dapat lebih baik. Adapun saran-saran untuk penelitian selanjutnya antara lain sebagai berikut :

1. Untuk pencampuran bahan sebaiknya tidak menggunakan kadar styrofoam yang lebih besar dari $60 \%$ karena hasil kuat tekan pada sampel dengan kadar styrofoam $60 \%$ menghasilkan kuat tekan yang kecil.

2. Gunakan faktor air semen (fas) yang lebih kecil dari penelitian ini karena pada kadar styrofoam sebesar $60 \%$ akan menghasilkan campuran yang sangat cair.

3. Perlu dilakukan penelitian lebih lanjut mengenai batako ringan tetapi dengan menggunakan campuran bahan ringan yang berbeda, misalnya batu apung

\section{DAFTAR PUSTAKA}

1. ACI 318-83M, Standar Building Code Requirements For Reinforce Concrete.

2. Giri. I.B.D, dkk. (2008). "Kuat Tarik Belah dan kuat lentur beton dengan penambahan

Styrofoam (STYROCON)". Jurnal Ilmiah Teknik Sipil Vol.12 Universitas Udayana Denpasar. Bali.

3. Nawy Edward G. (1990). Beton Bertulang Suatu Pendekatan Dasar. PT ERESCO. Bandung.

4. Neville, A.M, and Brooks, J.J. (1987). Concrete Technology. First Edition. Longman Scientific \& Technical. England.

5. SKSNI T-15-1991, Tata Cara Perhitungan Struktur Beton Untuk Bangunan Gedung.
6. SNI 4810:2013, Tata Cara Pembutan dan Perawatan Spesimen Uji Beton di Lapangan.

7. SNI 03-1970-1990, Metode Pengujian Berat Jenis Dan Penyerapan Agregat Halus.

8. SNI 03-2874 2002, Tata Cara Perhitungan Struktur Beton Untuk Bangunan Gedung.

9. SNI 03-4142-1996, Metode Pengujian Jumlah Bahan Dalam Agregat Yang Lolos Saringan No. 200 (0,075 mm).

10. SNI 03-4431-1997, Metode Pengujian Kuat Lentur Normal Dengan Dua Titik Pembebanan.

11. SNI 03-4804-1998, Metode Pengujian Bobot Isi dan Rongga Udara Dalam Agregat.

12. SNI 15-2049-2004, Semen Portland

13. SNI-03-0349-1989, StandarBata Beton Untuk Pasangan Dinding

14. Tjokrodimuljo,K. (1992). Teknologi Beton. Buku Ajar Teknik Sipil Universitas Gadjah Mada. Yogyakarta.

15. Tjokrodimuljo,K. (2007). Teknologi Beton. Nafiri. Yogyakarta.

16. Tri Mulyono. (2003). Teknologi Beton. Universitas Negeri Jakarta. Jakarta.

17. Wang Chu-Kia and Salmon Charles G.(1990) Disain Beton Bertulang. Edisi Ke empat. Erlangga. Jakarta. 